\title{
APPLICATION OF SYNDEMICS THEORY IN UNDERSTANDING HEALTH AND ECONOMIC IMPACTS OF GLOBAL PANDEMIC FOR THERAPISTS IN MASSAGE PARLORS
}

\author{
Yulsy Agatha \\ Occupational Health and Safety, Faculty of Public Health, \\ Universitas Esa Unggul, Jakarta
}

\begin{abstract}
Background: Syndemic or pandemic synergy refers the impact of a pandemic on more than one aspect of human life. One aspect affected by the COVID-19 pandemic is entrepreneurship, especially massage services because its business activities are closely related to physical contact between therapists and customers. This study aimed to analyze the health and economic impacts of COVID-19 pandemic experienced by therapists at massage parlors.

Subjects and Method: A cross-sectional study was conducted in Tangerang, Banten, Indonesia. A sample of 75 massage therapists was selected for this study. The dependent variables were health (length of absence from work due to illness) and economic (amount of income/month). The independent variable was the COVID-19 pandemic. The data were collected by questionnaire. Data were analyzed using the Wilcoxon test.

Results: There were difference of health and economic condition before and during the COVID-19 pandemic $(\mathrm{p}<0.001)$. The average day off work due to illness before the COVID-19 pandemic was 2 days, with the highest cause was low back pain (40.0\%). The average day off work due to illness during the COVID-19 pandemic was 14 days, with the highest cause was COVID-19 infection (60.0\%). The average income during the COVID-19 pandemic (Mean= IDR 1,800,000) was lower than before the COVID-19 pandemic (Mean = IDR 3,000,000).
\end{abstract}

Conclusion: COVID-19 pandemic has health and economic impacts in massage therapists.

Keywords: syndemic, occupational health, massage therapist.

\section{Correspondence:}

Yulsy Agatha. Universitas Esa Unggul. Jl. Arjuna Utara 9, Jakarta, Indonesia. Email: yulsy.email@gmail.com. Mobile: +6282111192989. 